\title{
Downregulation of miR-484 is associated with poor prognosis and tumor progression of gastric cancer
}

\author{
Ying Li, Yusong Liu, Jie Yao, Rui Li and Xiaocheng Fan ${ }^{*}$
}

\begin{abstract}
Background: Gastric cancer is one of the most common cancers leading to high cancer mortality. MicroRNA-484 (miR-484) has been evaluated as a biomarker for various types of cancers. The subject of this study is to investigate the functional role of miR-484 in gastric cancer.

Methods: The expression of miR-484 in gastric cancer was analyzed by quantitative real-time polymerase chain reaction (qRT-PCR) assay. Kaplan-Meier survival and Cox regression analyses were employed to explore the prognostic significance of miR-484 in gastric cancer. The functional role of miR-484 in gastric cancer was determined by CCK-8 and Transwell assays.

Results: The results showed that miR-484 was significantly downregulated in gastric cancer tissues and cell lines. The downregulation of miR-484 was closely related to differentiation, lymph node metastasis, TNM stage, and poor prognosis. Cox regression analyses demonstrated that miR-484 was an independent prognosis indicator for gastric cancer patients. Additionally, the downregulation of miR-484 enhanced cell proliferation, migration, and invasion in gastric cancer cells.

Conclusion: These data demonstrated that miR-484 can serve as a potential prognostic biomarker and therapeutic target for gastric cancer and it may be involved in the progression of gastric cancer.
\end{abstract}

Keywords: Gastric cancer, microRNA-484, Proliferation, Migration, Invasion, Prognosis

\section{Introduction}

Gastric Cancer is a kind of common malignancy with poor prognosis worldwide [1]. A variety of factors are reported to be associated with the development of gastric cancer, such as irregular diet, genetic and epigenetic influence [2]. Due to the lack of typical early symptoms, gastric cancer patients are always diagnosed at advanced stages [3]. The detailed knowledge of the molecular characteristics and the identification of new biomarkers are beneficial for the treatment of gastric cancer. Therefore,

\footnotetext{
* Correspondence: fanghaow35557@163.com

Department of Oncology, Jining Hospital of Traditional Chinese Medicine, Jining, Shandong 272000, China
}

finding the biomarker for early diagnosis, prognosis, and treatment of gastric cancer is of great importance.

MicroRNAs (miRNAs, 20-24 nucleotides in length) are a series of non-coding RNAs, which have vital roles in the regulation of gene expression at the posttranscriptional level via binding to the 3 '-UTR of target mRNAs [4]. Meanwhile, miRNAs participate in the regulation of a variety of human proteins, which makes it easier to affect the genetic pathways [5]. Currently, miRNA has been reported to act as oncogenes or antioncogenes in the initiation and development of various cancers [6-10]. For example, miR-423-3p acts as an oncogene and promotes cell proliferation, migration, and invasion of lung cancer [11]. MiRNAs also have

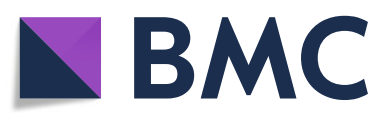

(C) The Author(s). 2020 Open Access This article is licensed under a Creative Commons Attribution 4.0 International License, which permits use, sharing, adaptation, distribution and reproduction in any medium or format, as long as you give appropriate credit to the original author(s) and the source, provide a link to the Creative Commons licence, and indicate if changes were made. The images or other third party material in this article are included in the article's Creative Commons licence, unless indicated otherwise in a credit line to the material. If material is not included in the article's Creative Commons licence and your intended use is not permitted by statutory regulation or exceeds the permitted use, you will need to obtain permission directly from the copyright holder. To view a copy of this licence, visit http://creativecommons.org/licenses/by/4.0/ The Creative Commons Public Domain Dedication waiver (http://creativecommons.org/publicdomain/zero/1.0/) applies to the data made available in this article, unless otherwise stated in a credit line to the data. 
been demonstrated to be implicated in the development, progression, and metastasis of gastric cancer. MiR-196a could promote the invasion and metastasis of gastric cancer by targeting SFRP1; miR-383-5p was downregulated and might act as a tumor suppressor for gastric cancer, and miR-374a has been reported to act as a biomarker for the diagnosis and prognosis of gastric cancer [12-14].

In the present study, miR-484 was investigated in the regulation of gastric cancer. MiR-484 was suggested to play a role in the progression of lung cancer by inhibiting the apoptosis of the cell [15]. It is also reported that miR-484 inhibits cell proliferation of cervical cancer and breast cancer [16, 17]. Additionally, mir-484 has been demonstrated to be down-regulated in gastric cancer [18-20], however, the specific mechanism of miR-484 on the modulation of gastric cancer has not been reported. Therefore, the subject of this study is to investigate the role of miR-484 in the prognosis and progression of gastric cancer, providing considerable therapeutic strategies against gastric cancer.

\section{Materials and methods}

\section{Patients and tissue samples collection}

The paired gastric cancer tissue and matched adjacent normal tissue specimens used for the investigation were collected from 124 patients with gastric cancer admitted to Binzhou Medical University Hospital, from January 2011 to December 2013. The isolated samples were confirmed with pathology diagnosis following the International Union against Cancer. The collected tissues were snap-frozen in liquid nitrogen and stored at $-80^{\circ} \mathrm{C}$ for further analysis. Additionally, all the patients had not received any anti-tumor therapies, and a 5-year follow up survey was carried to collect the survival status. Meanwhile, the clinicopathological information of the patients, including age, gender, tumor size, differentiation, lymph node metastasis, and TNM stage are listed in Tables 1 and 2. All participants signed written informed consent in this study. The research was approved by the Ethics Committee of Binzhou Medical University Hospital.

\section{Cell lines and transfection}

Gastric cancer cell lines (HGC-27, SNU-1, AGS, NCIN87) and a normal gastric mucous membrane cell line (GES-1) were purchased from Shanghai Cell Bank of the Chinese Academy of Sciences. All the cells were incubated in the RPMI1640 medium with $10 \%$ fetal bovine serum (FBS), in a humidified incubator at $37{ }^{\circ} \mathrm{C}$ with $5 \%$ $\mathrm{CO}_{2}$. For the cell transfection, miR-484 mimic, mimic negative control (NC), miR-484 inhibitor, inhibitor NC (RiboBio, Guangzhou, China) were used for the overexpression and knockdown of miR-484, and the Lipofectamine 2000 Reagent (Invitrogen, USA) was employed
Table 1 Correlation between miR-484 expression levels and clinical features in gastric cancer patients

\begin{tabular}{|c|c|c|c|c|}
\hline \multirow[t]{2}{*}{ Parameters } & \multirow{2}{*}{$\begin{array}{l}\text { Cases No. } \\
(n=124)\end{array}$} & \multicolumn{2}{|c|}{ miR-484 expression } & \multirow[t]{2}{*}{$P$} \\
\hline & & Low $(n=69)$ & High $(n=55)$ & \\
\hline \multicolumn{5}{|l|}{ Age } \\
\hline$<60$ & 63 & 33 & 30 & \multirow[t]{2}{*}{0.269} \\
\hline$\geq 60$ & 61 & 36 & 25 & \\
\hline \multicolumn{5}{|l|}{ Gender } \\
\hline Male & 76 & 37 & 39 & \multirow[t]{2}{*}{0.632} \\
\hline Female & 48 & 32 & 16 & \\
\hline \multicolumn{5}{|l|}{ Differentiation } \\
\hline Well + Moderate & 71 & 29 & 42 & \multirow[t]{2}{*}{0.006} \\
\hline Poor & 53 & 40 & 13 & \\
\hline \multicolumn{5}{|l|}{ T Stage } \\
\hline $\mathrm{T}_{1}-\mathrm{T}_{2}$ & 64 & 34 & 30 & \multirow[t]{2}{*}{0.388} \\
\hline$T_{3}-T_{4}$ & 60 & 35 & 25 & \\
\hline \multicolumn{5}{|l|}{ Lauren classification } \\
\hline Intestinal & 68 & 33 & 25 & \multirow[t]{2}{*}{0.504} \\
\hline Diffused & 56 & 26 & 30 & \\
\hline \multicolumn{5}{|c|}{ Lymph node metastasis } \\
\hline Negative & 57 & 24 & 33 & \multirow[t]{2}{*}{0.015} \\
\hline Positive & 67 & 45 & 22 & \\
\hline \multicolumn{5}{|l|}{ Distant metastasis } \\
\hline Negative & 93 & 47 & 46 & \multirow[t]{2}{*}{0.005} \\
\hline Positive & 31 & 22 & 9 & \\
\hline \multicolumn{5}{|l|}{ TNM stage } \\
\hline $\mid-\|$ & 55 & 26 & 29 & \multirow[t]{2}{*}{0.002} \\
\hline$\| I \mid-I V$ & 69 & 43 & 26 & \\
\hline
\end{tabular}

Table 2 Multivariate Cox analysis of clinical parameters in relation to overall survival

\begin{tabular}{llll}
\hline Characteristics & \multicolumn{3}{l}{ Multivariate analysis } \\
\cline { 2 - 4 } & HR & $95 \% \mathrm{Cl}$ & $P$ \\
\hline miR-484 & 2.868 & $1.148-7.167$ & 0.024 \\
Age & 1.176 & $0.589-2.350$ & 0.645 \\
Gender & 1.276 & $0.611-2.664$ & 0.517 \\
Differentiation & 1.563 & $0.715-3.413$ & 0.263 \\
T stage & 1.529 & $0.760-3.076$ & 0.234 \\
Lauren classification & 1.426 & $0.707-2.879$ & 0.322 \\
Lymph node metastasis & 1.844 & $0.861-3.953$ & 0.116 \\
Distant metastasis & 2.172 & $1.032-4.570$ & 0.041 \\
TNM stage & 2.061 & $1.029-4.126$ & 0.041 \\
\hline
\end{tabular}


according to the instructions of the manufacturer. The sequence of miR-484 mimic is: 5'-UCAGGCUCAG UCCCCUCCCGAU-3', and the sequence of miR-484 inhibitor is: 5' - AUCGGGAGGGGACUGAGCCUGA-3'.

\section{RNA extraction and quantitative real-time polymerase chain reaction (qRT-PCR)}

The TRIzol reagent (Invitrogen, Carlsbad, CA, USA) was used to extract total RNA of tissues and cells. The extracted RNA reverse transcript to cDNA by a High Capacity cDNA Reverse Transcription Kit (Applied Biosystems, Foster City, CA), and stored at $-20{ }^{\circ} \mathrm{C}$. Next, qRT-PCR was utilized to investigate the expression of miR-484 in tissues and cells, which was carried out with the SYBR Green I Master Mix kit (Invitrogen) and ran on the 7300 Real-Time PCR System (Applied Biosystems, USA). The expression level was determined using the $2^{-\Delta \Delta \mathrm{Ct}}$ method and normalized to U6.

\section{Cell proliferation assay}

The transfection cells were seeded into a 96-well plate with a cell concentration of $5 \times 10^{3} / \mathrm{mL}$ per well. At 0 , $24,48,72 \mathrm{~h}, 10 \mu \mathrm{L}$ cell counting kit-8 (CCK-8) reagent (Dojindo, Kumamoto, Japan) was added to each well, and then incubated in a humidified incubator for $4 \mathrm{~h}$ at $37^{\circ} \mathrm{C}$ with $5 \% \mathrm{CO}_{2}$. The absorbance at $450 \mathrm{~nm}$ was measured by a microplate reader (Thermo Fisher Scientific). Experiments were repeated in triplicate.

\section{Transwell migration and invasion assay}

The 24-well transwell chambers (Multiskan MK3, Thermo, Waltham, MA, USA) with a pore size of $8 \mu \mathrm{m}$ polycarbonate membrane was employed to analyze the migration and invasion. For the migration assay, the transfected cells with the concentration of $2 \times 10^{5} / \mathrm{ml}$ were seeded into the upper compartment and then incubated in the culture medium without $\mathrm{FBS}$ at $37^{\circ} \mathrm{C}$ for $24 \mathrm{~h}$. While for the invasion assay, the upper chamber was coated with Matrigel (BD Biosciences, Franklin Lakes, NJ, USA). The lower chamber was filled the culture medium with $10 \%$ FBS as a chemoattractant. After incubating for $48 \mathrm{~h}$, the migrated cells were stained with $0.1 \%$ crystal violet and counted by a microscope.

\section{Statistical analysis}

All results are presented as mean \pm standard deviation (SD). Statistical analysis of the data was conducted with SPSS 20.0 software (SPSS, Inc., Chicago, IL, USA) and GraphPad Prism 5.0 software (GraphPad Software, Inc., Chicago, USA). The differences between the two groups are analyzed through Student's t-test. The correlation of miR-484 with clinicopathological features was evaluated by $x^{2}$ test. Kaplan-Meier analysis and Cox regression analysis were used to determine the prognostic significance of miR-484. The differences were considered to be significant when $P<0.05$.

\section{Results \\ Expression of miR-484 in gastric cancer tissues and cell lines}

The expression of miR-484 was analyzed by qRT-PCR in gastric cancer tissues and adjacent normal tissues. As shown in Fig. 1a, compared with adjacent normal tissues, miR-484 in gastric cancer tissues was significantly downregulated $(P<0.001)$. Additionally, the expression of miR-484 in four different gastric cancer cell lines and a normal cell line was investigated. The result showed that the expression of miR-484 in gastric cancer cell lines was lower than that in the normal cell lines, and the difference was significant $(P<0.001$, Fig. $1 b)$. The expression of miR-484 was different in four cancer cell lines, with the lowest expression appeared in NCI-N87 cell line, followed by HGC-27 cell line, and the expression of miR-484 in AGS and SNU-1 was a bit higher than that in the other two cell lines. Due to the relatively low expression, NCI-N87 and HGC-27 were selected for the following experiments.

The relationship between the expression of miR-484 and the clinicopathological features of gastric cancer patients According to the mean expression level of miR-484 (5.617), all 124 gastric cancer patients were divided into two groups: high expression group and low expression group. Next, the relationship between the expression of miR-484 and the clinicopathological features of gastric cancer patients was evaluated through $\chi^{2}$ test, the results are summarized in Table 1 . The results revealed that the expression of miR-484 was significantly related to differentiation $(P=0.006)$, lymph node metastasis $(P=0.015)$, distant metastasis $(P=0.005)$ and TNM stage $(P=0.002)$. Nevertheless, the age and gender of patients were not associated with the expression of miR-484 (all $P>0.05$ ).

\section{Prognostic value of miR-484 in gastric cancer}

Based on the expression of miR-484 and the overall survival information of gastric cancer patients from a 5year follow up survey, the Kaplan-Meier analysis was employed to assess the role of $\mathrm{miR}-484$ in the prognosis of gastric cancer. As shown in Fig. 2, the overall survival rate of patients with high expression of miR-484 was much higher than those with low expression of miR-484 (log-rank test $P=0.001)$. Furthermore, the multivariate Cox's hazard regression analysis was used to investigate the effect of miR-484 and other clinic clinicopathological features on the survival rate of gastric cancer patients. Results showed that the expression of miR-484 ( $\mathrm{HR}=$ $2.868,95 \% \mathrm{CI}=1.148-7.167, P=0.024)$, distant metastasis 
A

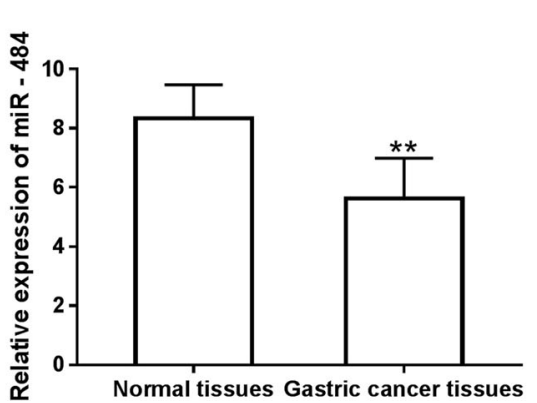

B

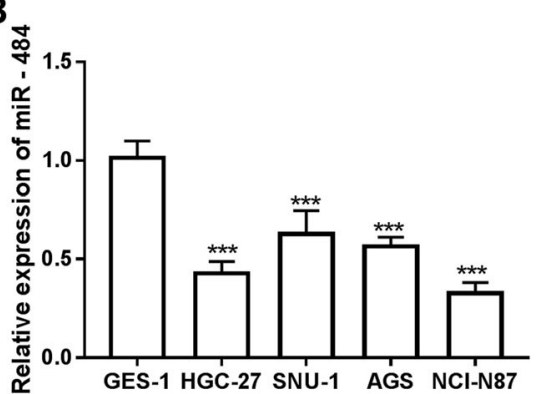

Fig. 1 Expression of miR-484 in gastric cancer tissues and cell lines. a. Expression of miR-484 was downregulated in gastric cancer tissues compared with adjacent normal tissues. ( ${ }^{* *} P<0.01$, $\left.{ }^{* *} P<0.001\right)$. b. Expression of miR-484 was decreased in gastric cancer cell lines (HGC-27, SNU-1, AGS, NCl-N87) compared with normal cell line GES-1. (***P<0.001)

$(\mathrm{HR}=2.172,95 \% \mathrm{CI}=1.032-4.570, P=0.041)$ and the TNM stage $(\mathrm{HR}=2.061,95 \% \mathrm{CI}=1.029-4.126, P=0.041)$ of patients are independent prognostic factors for 5-year overall survival in gastric cancer patients (Table 2).

\section{The role of miR-484 in cell proliferation, migration, and} invasion of gastric cancer

The HGC-27 and NCI-N87 were transfected with miR484 mimic or miR-484 inhibitor to evaluate the functional role of miR-484 in gastric cancer. The results in Fig. 3a showed that miR-484 mimic increased the expression of miR-484, and miR-484 was downregulated in the presence of miR-484 inhibitor, the difference was significant $(P<0.01)$. Then the cell proliferation capacity

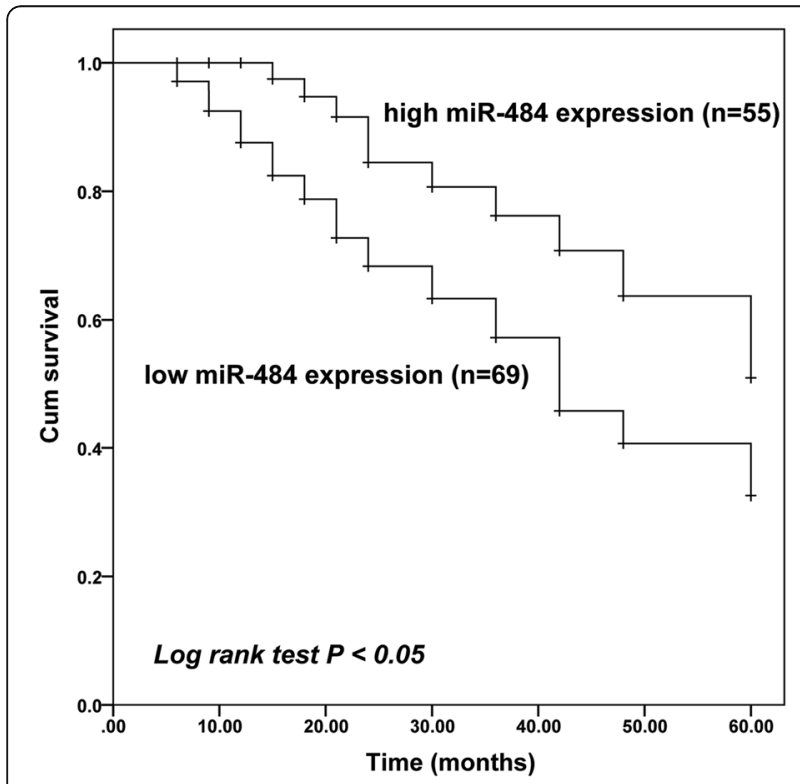

Fig. 2 Kaplan-Meier survival curves for gastric cancer patients based on the expression of miR-484. P value was calculated using the logrank test. Patients with low miR-484 expression had a shorter survival time than those with high miR-484 expression was evaluated through the CCK-8 assay. The proliferation of HGC-27 and NCI-N87 with high miR-484 expression was inhibited, while the cell lines with low miR-484 expression were promoted, and the difference was significant $(P<0.05$, Fig. $3 b)$. Meanwhile, the migration and invasion of the cell lines were also investigated. The results suggested that the high expression of miR484 increased by miR-484 mimic led to an inhibition of migration, whereas the downregulation of miR-484 inhibited by miR-484 inhibitor enhanced the migration, and the same effects were exerted on the invasion of the cell lines $(P<0.01$, Fig. $4 \mathrm{a}$ and $\mathrm{b})$.

\section{Discussion}

Gastric cancer is considered to be a highly lethal malignancy, due to its terrible proliferation, migration, and invasion, which can lead to high mortality and poor prognosis. The modular and cellular factors that governing these processes remain unclear [21]. Multiple studies have reported that microRNAs could regulate target mRNAs and its abnormal expression was closely related to the migration, invasion, and proliferation of various cancers [10, 22-24]. For instance, miR-593 can inhibit the migration and invasion of non-small cell lung cancer cells by targeting SLUG-associated signaling pathways [25]. MiRNAs have different behaviors in various cancers. MiR-601 acts as an oncogene in gastric cancer, which was upregulated and related with the poor prognosis of gastric cancer [26]. On the other hand, miR-601 was also a prognosis marker of breast cancer, because its downregulation could promote the proliferation, migration, and invasion of breast cancer cells [27]. For gastric cancer, a variety of miRNAs have been reported to play a role in its proliferation, migration, and invasion, such as miR-4317, miR-501-5p, miR-214 and so on [28-30]. Moreover, miR-214 was also demonstrated to enhance the invasion of breast cancer cells, and it was upregulated in breast cancer, which is opposite to the expression in gastric cancer [31]. 
A
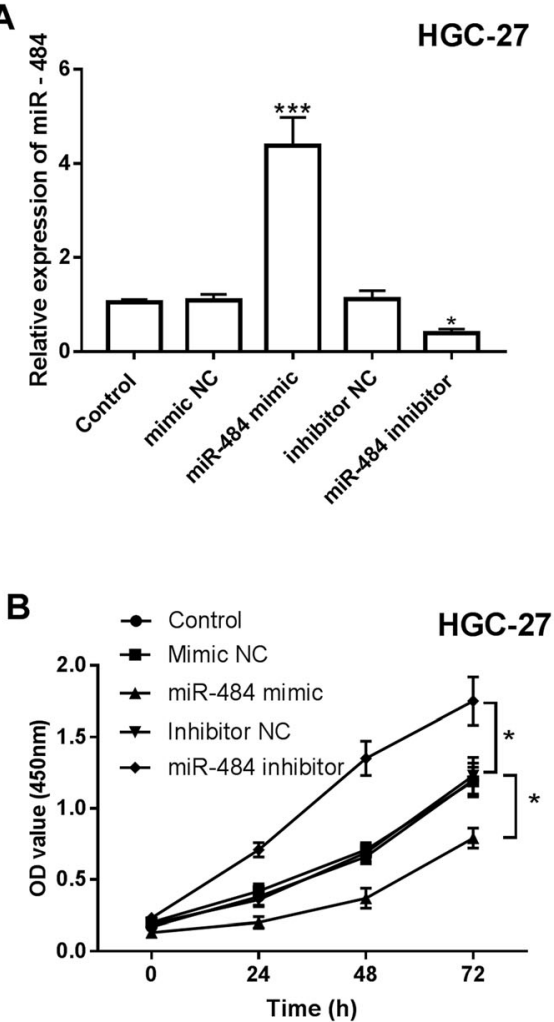

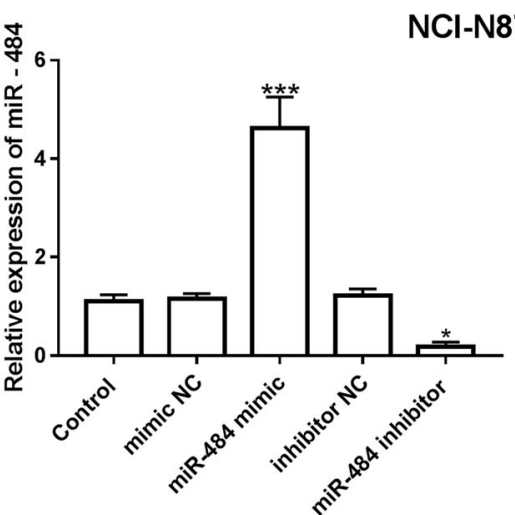

NCI-N87

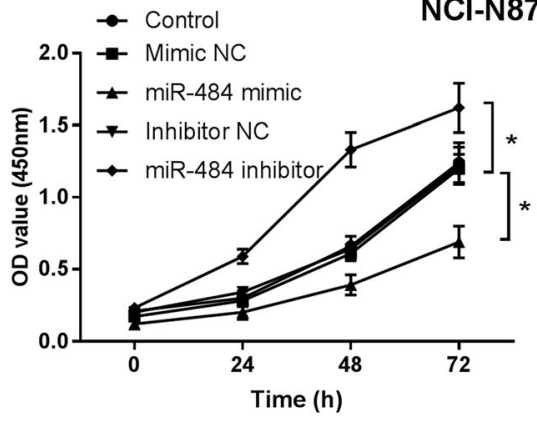

Fig. 3 Effect of miR-484 on the cell proliferation of HGC-27 and NCI-N87. a. Expression of miR-484 in the presence of miR-484 mimic or miR-484 inhibitor $\left({ }^{*} P<0.05,{ }^{* *} P<0.001\right)$. b. Overexpression of miR-484 inhibited the proliferation of gastric cancer cells $\left({ }^{*} P<0.05\right)$

In the present study, the role of miR-484 in the proliferation, migration, and invasion of gastric cancer was studied, and we found the expression of miR-484 was downregulated in gastric cancer tissues compared with paired adjacent normal tissues. Moreover, the expression of miR-484 was associated with differentiation, lymph node metastasis, and TNM stage. From these results, it can be inferred that miR-484 may be a tumor suppressor, which is consistent with previous studies [18-20]. Furthermore, the association of miR-484 with tumor differentiation, lymph node metastasis and TNM stage of the patients was found, indicating the potential role of miR-484 in the development of gastric cancer. Additionally, based on the survival information and the clinical features of patients, the Kaplan-Meier curve and Cox regression analyses were employed to explore the clinical significance of miR-484. From the results, we found that the patients with low expression of miR-484 had shorter survival time, which indicated that the downregulation of miR-484 was associated with poor overall survival.

Previous studies have demonstrated the dysregulation of miRNAs that play roles in cell proliferation, migration, and invasion of various cancers. For example, the downregulation of $\mathrm{miR}-449 \mathrm{a}$ exerted inhibitory effect on the proliferation, migration, and invasion of cervical cancer [8]. The overexpression of miR-200 could suppress tumor proliferation in colorectal cancer [32]. Actually, the role of miR-484 in a certain type of cancer is still a controversial issue. Recent research has found the dysregulation of miR-484 in various cancers, and its expression was different. The expression of miR-484 in lung cancer was increased, but it was downregulated in cervical cancer and metastatic renal cell carcinoma [16, 33, 34]. It also has been reported that miR-484 was highly specific for prostate cancer, which could make it act as a prostate cancer screening biomarker [35]. In hepatocellular carcinoma, miR-484 has an oncogenic role by targeting TUSC5 [36]. Moreover, miR-484 could act as the biomarker for many other cancers, including lung cancer, breast cancer, cervical cancer and colorectal cancer [15, 16, 37]. In the present study, the upregulation of miR-484 inhibited the proliferation, migration, and invasion of gastric cancer cells, which suggested that miR-484 might be involved in the progression of gastric cancer.

However, there are also some limitations in our study. Previous studies have demonstrated that miR-484 can reduce the expression of a series of oncogenes, such as ZEB1, SMAD2, etc., inhibit the epithelial-mesenchymal 

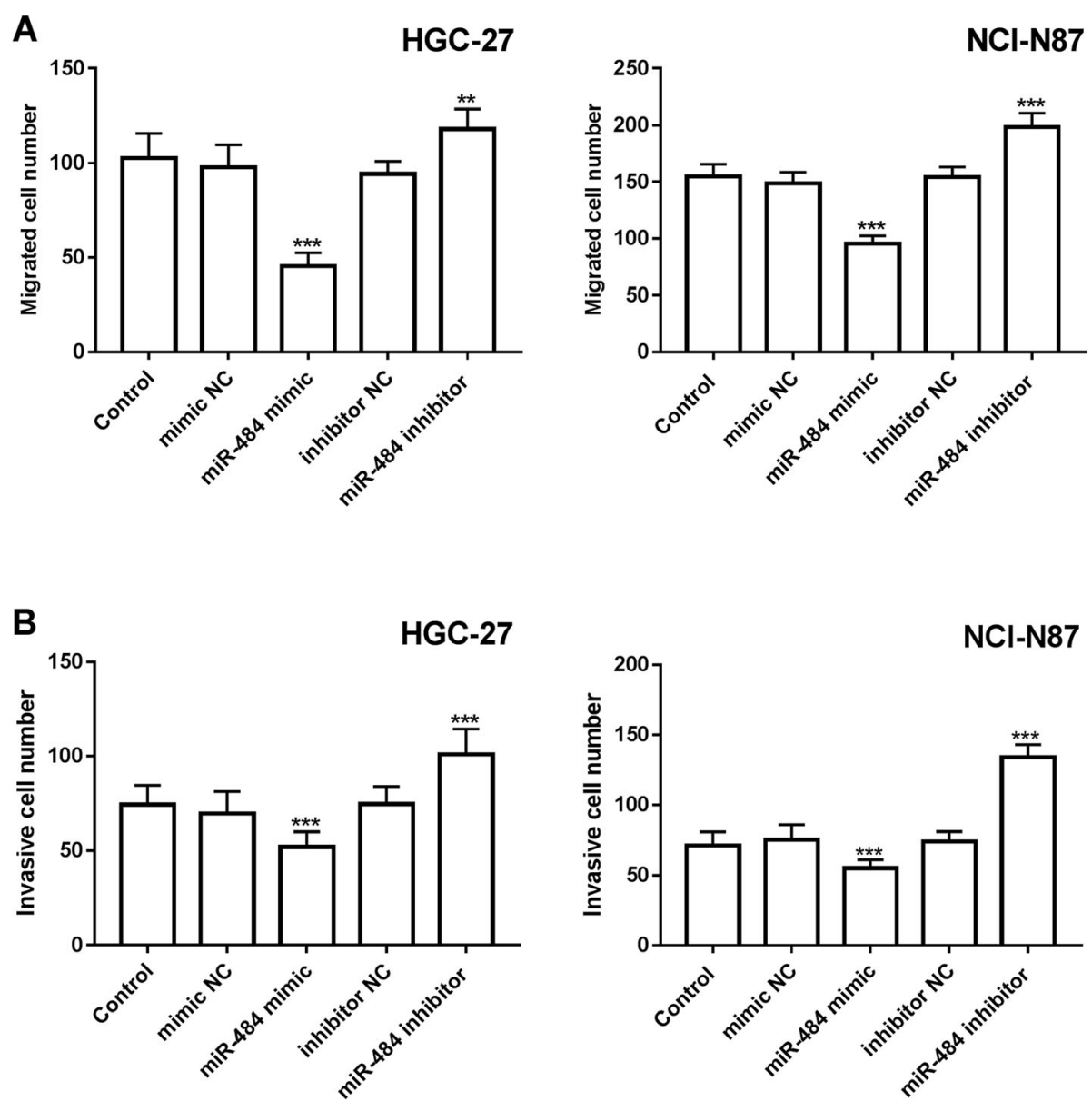

Fig. 4 Effect of miR-484 on the migration and invasion of HGC-27 and NCI-N87. a. Knockdown of miR-484 enhances the migration of gastric cancer cells $\left({ }^{* *} P<0.01,{ }^{* * *} P<0.001\right)$. b. Reduction of miR-484 promotes the invasion of gastric cancer cells $\left({ }^{* * *} P<0.001\right)$

transition (EMT) of tumor cells, or regulate the extracellular signal-regulated kinase $1 / 2$ signaling [16, 34, 38]. The precise molecular mechanisms underlying the role of miR-484 should be investigated in further studies. On the other hand, only a limited number of samples were included in the current study and increased sample size should be used in the future to validate the accuracy of miR-484 as a biomarker.

To summarize, the present study indicated the downregulation of miR-484 was associated with the poor overall survival of gastric cancer patients, which makes it possible to act as a candidate prognostic biomarker. The overexpression of miR-484 in gastric cancer leads to inhibited cell proliferation, migration, and invasion, indicating that miR-484 may be a therapeutic target for the treatment of gastric cancer.

\section{Abbreviations}

miR-484: microrna-484; aRT-PCR: Quantitative real-time polymerase chain reaction; miRNAs: MicroRNAs; FBS: Fetal bovine serum; NC: Negative control; CCK-8: Cell counting kit-8; SD: Standard deviation; EMT: Epithelialmesenchymal transition
Acknowledgments

We thank very much Dr. Guo Chen, Dr. Jinliang Wan, Dr. Zhenbo Wang, Dr. Lei Li, Dr. Hongying Jia, Dr. Shaozhi Xing, Dr. Shaoshui Chen for their supports on clinical sample collection and data analysis.

\section{Authors' contributions}

Ying Li and Xiaocheng Fan contributed to conceptualization, methodology, data interpretation, and wrote the manuscript. Ying Li, Yusong Liu, Jie Yao, Rui Li, Xiaocheng Fan conducted the experiments, analyzed the data, and the preparation of the manuscript. All authors read and approved the final version.

\section{Funding}

This work was supported by the fund of Binzhou Medical University Hospital [No. BY2015KJ25].

Availability of data and materials

The datasets used during the current study are available from the corresponding author on reasonable request.

Ethics approval and consent to participate

All participants signed written informed consent in this study. The research was approved by the Ethics Committee of Binzhou Medical University Hospital.

Consent for publication

Written informed consent for publication was obtained from each participant 


\section{Competing interests}

The authors declare that they have no competing interests.

Received: 12 November 2019 Accepted: 10 March 2020 Published online: 20 March 2020

\section{References}

1. Futami T, Kawase T, Mori K, Asaumi M, Kihara R, Shindoh N, et al. Identification of a novel oncogenic mutation of FGFR4 in gastric cancer. Sci Rep. 2019;9(1):14627

2. Carcas. Gastric cancer review. J carcinog. 2014;13:14.

3. Sasako M, Sakuramoto S, Katai H, Kinoshita T, Furukawa H, Yamaguchi T, et al. Five-year outcomes of a randomized phase III trial comparing adjuvant chemotherapy with S-1 versus surgery alone in stage II or III gastric cancer. J Clin Oncol. 2011:29(33):4387-93.

4. Zhang Y, Wang Z, Gemeinhart RA. Progress in microRNA delivery. J Control Release. 2013;172(3):962-74.

5. Filipowicz W, Bhattacharyya SN, Sonenberg N. Mechanisms of posttranscriptional regulation by microRNAs: are the answers in sight? Nat Rev Genet. 2008:9(2):102-14

6. Li J, Zou X. MiR-652 serves as a prognostic biomarker in gastric cancer and promotes tumor proliferation, migration, and invasion via targeting RORA. Cancer biomarkers. 2019; undefined(undefined):1-9.

7. Wang S, Gao B, Yang H, Liu X, Wu X, Wang W. MicroRNA-432 is downregulated in cervical cancer and directly targets FN1 to inhibit cell proliferation and invasion. Oncol Lett. 2019;18(2):1475-82.

8. Wang L, Zhao Y, Xiong W, Ye W, Zhao W, Hua Y. MicroRNA-449a Is Downregulated in Cervical Cancer and Inhibits Proliferation, Migration, and Invasion. Oncol Res Treat. 2019:42(11):1-7.

9. Han X, Du C, Chen Y, Zhong X, Wang F, Wang J, et al. Overexpression of miR-939-3p predicts poor prognosis and promotes progression in lung cancer. Cancer Biomark. 2019;25(4):325-32.

10. Wang X, Zhou Z, Zhang T, Wang M, Xu R, Qin S, et al. Overexpression of miR-664 is associated with poor overall survival and accelerates cell proliferation, migration and invasion in hepatocellular carcinoma. Oncotargets Ther. 2019;12(undefined):2373-81.

11. Wang R, Li G, Zhuang G, Sun S, Song Z. Overexpression of microRNA-423$3 p$ indicates poor prognosis and promotes cell proliferation, migration, and invasion of lung cancer. Diagn Pathol. 2019;14(1):53.

12. Ji R, Zhang X, Gu H, Ma J, Wen X, Zhou J, et al. MiR-374a-5p: a new target for diagnosis and drug resistance therapy in gastric Cancer. Mol Ther Nucleic Acids. 2019:18:320-31.

13. Wei C, Gao JJ. Downregulated miR-383-5p contributes to the proliferation and migration of gastric cancer cells and is associated with poor prognosis. PeerJ. 2019;7:e7882.

14. Feng C, She J, Chen X, Zhang Q, Zhang X, Wang Y, et al. Exosomal miR196a-1 promotes gastric cancer cell invasion and metastasis by targeting SFRP1. Nanomedicine (Lond). 2019:14:1743-5889..

15. Li T, Ding ZL, Zheng YL, Wang W. MiR-484 promotes non-small-cell lung cancer (NSCLC) progression through inhibiting Apaf-1 associated with the suppression of apoptosis. Biomed Pharmacother. 2017;96:153-64.

16. Hu Y, Xie H, Liu Y, Liu W, Liu M, Tang H. MiR-484 suppresses proliferation and epithelial-mesenchymal transition by targeting ZEB1 and SMAD2 in cervical cancer cells. Cancer Cell Int. 2017;17:-36.

17. Ye F-G, Song C-G, Cao Z-G, Xia C, Chen D-N, Chen L, et al. Cytidine Deaminase Axis modulated by miR-484 differentially regulates cell proliferation and Chemoresistance in breast Cancer. Cancer Res. 2015;75(7): 1504-15.

18. Konishi H, Ichikawa D, Komatsu S, Shiozaki A, Tsujiura M, Takeshita $H$, et al. Detection of gastric cancer-associated microRNAs on microRNA microarray comparing pre- and post-operative plasma. Br J Cancer. 2012;106(4):740-7.

19. Treece AL, Duncan DL, Tang W, Elmore S, Morgan DR, Dominguez RL, et al. Gastric adenocarcinoma microRNA profiles in fixed tissue and in plasma reveal cancer-associated and Epstein-Barr virus-related expression patterns. Lab Investig. 2016;96(6):661-71

20. Zare A, Ahadi A, Larki P, Omrani MD, Zali MR, Alamdari NM, et al. The clinical significance of miR-335, miR-124, miR-218 and miR-484 downregulation in gastric cancer. Mol Biol Rep. 2018:45(6):1587-95.

21. Garzon AE. MicroRNAs in Cancer. Annu Rev Med. 2009;60(1):167-79.

22. Hata A, Kashima R. Dysregulation of microRNA biogenesis machinery in cancer. Crit Rev Biochem Mol Biol. 2016;51(3):121-34.
23. Tavazoie S, Alarcón C, Oskarsson T, Padua D, Wang Q, Bos P, et al Endogenous human microRNAs that suppress breast cancer metastasis. Nature. 2008;451(7175):147-52.

24. Liu H, Ma L, Wang J. Overexpression of miR-25 is associated with progression and poor prognosis of cholangiocarcinoma. Exp Ther Med. 2019;18(4):2687-94.

25. Wei F, Wang M, Li Z, Wang Y, Zhou Y. MiR593 inhibits proliferation and invasion and promotes apoptosis in nonsmall cell lung cancer cells by targeting SLUGassociated signaling pathways. Mol Med Rep. 2019; 20(undefined):5172-82.

26. Min C, Zhang A, Qin J. Increased expression of miR-601 is associated with poor prognosis and tumor progression of gastric cancer. Diagn Pathol. 2019;14(1):107.

27. Hu JY, Yi W, Wei X, Zhang MY, Xu R, Zeng LS, et al. MiR-601 is a prognostic marker and suppresses cell growth and invasion by targeting PTP4A1 in breast cancer. Biomed Pharmacother. 2016;79:247-53.

28. Hu X, Zhang M, Miao J, Wang X, Huang C. MiRNA-4317 suppresses human gastric cancer cell proliferation by targeting ZNF322. Cell Biol Int. 2018;42(8): 923-30.

29. Wang R, Sun Y, Yu W, Yan Y, Qiao M, Jiang R, et al. Downregulation of miRNA-214 in cancer-associated fibroblasts contributes to migration and invasion of gastric cancer cells through targeting FGF9 and inducing EMT. J Exp Clin Cancer Res. 2019;38(1):20

30. Fan D, Ren B, Yang X, Liu J, Zhang Z. Upregulation of miR-501-5p activates the wnt/ $\beta$-catenin signaling pathway and enhances stem cell-like phenotype in gastric cancer. J Exp Clin Cancer Res. 2016:35(1):177.

31. Wang F, Lv P, Liu X, Zhu M, Qiu X. MicroRNA-214 enhances the invasion ability of breast cancer cells by targeting p53. Int J Mol Med. 2015;35(5): 1395-402.

32. Carter JV, O'Brien SJ, Burton JF, Oxford BG, Stephen V, Hallion J, et al. The microRNA-200 family acts as an oncogene in colorectal cancer by inhibiting the tumor suppressor RASSF2. Oncol Lett. 2019;18(4):3994-4007.

33. Merhautova J, Hezova R, Poprach A, Kovarikova A, Radova L, Svoboda M, et al. MiR-155 and miR-484 Are Associated with Time to Progression in Metastatic Renal Cell Carcinoma Treated with Sunitinib. BioMed Res Int. 2015:941980.

34. Zhang Q, Li X, Chen Z. LncRNA H19 promotes epithelial-mesenchymal transition (EMT) by targeting miR-484 in human lung cancer cells. J Cell Biochem. 2018;119(6):4447-57.

35. Guo X, Han T, Hu P, Zhu C, Wang Y, Chang S. Five microRNAs in serum as potential biomarkers for prostate cancer risk assessment and therapeutic intervention. Int Urol Nephrol. 2018;50(12):2193-200.

36. Wang S, Wang W, Han X, Wang Y, Ge Y, Tan Z. Dysregulation of miR484TUSC5 axis takes part in the progression of hepatocellular carcinoma. J Biochem. 2019;166(3):271-9.

37. Xie S, Ge Q, Wang X, Sun X, Kang Y. Long non-coding RNA ZFAS1 sponges miR-484 to promote cell proliferation and invasion in colorectal cancer. Cell Cycle. 2018:17(2):154-61.

38. Yi R, Feng J, Yang S, Huang X, Liao Y, Hu Z, et al. MiR-484/MAP2/C-Mycpositive regulatory loop in glioma promotes tumor-initiating properties through ERK1/2 signaling. J Mol Histol. 2018;49(2):209-18.

\section{Publisher's Note}

Springer Nature remains neutral with regard to jurisdictional claims in published maps and institutional affiliations.

Ready to submit your research? Choose BMC and benefit from

- fast, convenient online submission

- thorough peer review by experienced researchers in your field

- rapid publication on acceptance

- support for research data, including large and complex data types

- gold Open Access which fosters wider collaboration and increased citations

- maximum visibility for your research: over $100 \mathrm{M}$ website views per year

At BMC, research is always in progress.

Learn more biomedcentral.com/submissions 